\title{
OS SENTIDOS DO POLÍTICO EM DISCURSOS DE CAMPANHA
}

\author{
Aloisio de Medeiros Dantas (UFPB)
}

Com esta pesquisa, procuramos analisar os diferentes sentidos que atravessam o discurso político, num contexto de processo seletivo eleitoral. Empiricamente, estudaremos as cartas-programa dos candidatos a reitor da Universidade Federal da Paraíba.Com este estudo, pretendemos responder às seguintes questões: como os discursos políticos se distribuem na sociedade? Há um discurso político universitário que tenha sentidos diferentes daqueles da sociedade em geral? Nosso objetivo é verificar se os textos veiculados numa instituição trazem os sentidos próprios a essa instituição (em nosso caso específico, o discurso acadêmico) e como esses sentidos se instauram como políticos.

Em Análise de Discurso, há conceitos já estabelecidos como os de formação discursiva, interdiscursividade, texto, discurso, entretanto há outros que precisam ser bem mais trabalhados. Cito apenas alguns: sujeito, ideologia, sentido. Esta pesquisa faz as seguintes questões: quando fala de "sentido", de que "sentido" está falando a Análise de Discurso? Em que região situamos o não-sentido? De que modo devemos caracterizar o silêncio?

Este ensaio precisa responder a questões de natureza teórica e analítica. Responderemos inicialmente às questões teóricas e saberemos se, com essas respostas, podemos esclarecer nossas preocupações com o discurso político de campanha.

Nossa primeira referência, que tomamos como ponto de partida, será a noção que Barthes (1987) tem de sentido. Segundo o autor, sentido não são as palavras ou grupo de palavras que aparecem nos dicionários e nas gramáticas, apreendido por conhecimento da língua (que não lhe é suficiente), mas as conotações, os sentidos segundos, que podemos recuperar por associações e por relações. Nessa reflexão, surgem alguns postulados que necessitam de esclarecimentos: o sentido não é apenas lingüístico, há sentidos literais 
(denotativos) e sentidos transferidos (conotativos), precisamos distinguir língua de textos e discursos. Esses princípios são sabiamente inerentes a quem estuda a linguagem, entretanto essa distinção entre o lingüístico e o discursivo (assim entendemos a oposição denotativo $\mathrm{x}$ conotativo) tem causado alguns problemas para a $\mathrm{AD}$, principalmente quando diz respeito a aspectos de natureza enunciativa (entre os lingüistas) e a aspectos de natureza documental (entre historiadores e outros pesquisadores não-lingüistas).

É tentando diminuir essa dificuldade que estudamos o sentido nos discursos. A leitura de um romance pode nos ajudar nessa tarefa. Em Os leopardos de Kafka, de Moacyr Scliar, o personagem central encontra-se às voltas com um texto de Kafka, ao qual atribuí um sentido revolucionário, partindo das suas leituras do Manifesto Comunista, de Marx, de livros de Lenin e de Trotsky; entretanto, o próprio autor do texto (num diálogo entre Benjamin Kantarovitch e Franz Kafka, conforme criação de Scliar) desfaz o equívoco, afirmando que ele escreveu o texto para uma revista. Aqui, há quatro realidades fundamentais para a compreensão dos sentidos do discurso: o texto, o discurso, o sujeito e a língua. O texto tem um sentido que tanto pode estar escondido e inacessível à leitura, como pode estar totalmente aberto; essas variáveis dependem do sujeito e do discurso, que são caracterizados por sua memória e interdiscursividade.

No romance em questão, Benjamin está imerso em uma ideologia marxista revolucionária e todas as suas leituras são intermediadas pelo Manifesto Comunista, o que dá um sentido diferente ao texto. Entretanto, nada disso seria possível sem o lugar do equívoco na língua; é porque a língua, em alguns momentos, se constitui de equívocos que os sentidos do discurso sempre podem ser outros. Estamos dizendo que os elementos da língua não significam na abstração das estruturas, e a sua realização como textos, atravessados por discursos, nos dá a materialidade de seus sentidos. Com essa reflexão, concordamos com GUIMARÃEs (1999), para quem a forma da língua se relaciona com a história do texto, a forma da língua significa por suas relações com a história dos textos em que aparece. Desse modo, o sentido articula a memória discursiva e as formas lingüísticas na caracterização dos contornos da textualidade. Essa posição teórica vem, na linha do pensamento de Eduardo Guimarães, definir o sentido como uma enunciação historicamente constituída. Segundo GUIMARÃES (1995:66-70), "o sentido deve ser tratado como 
discursivo e definido a partir do acontecimento enunciativo (...) aquilo que significa, os efeitos de sentido são efeitos do interdiscurso no acontecimento (...) pela interdiscursividade e sua necessária intertextualidade, o sentido não é formal, mas tem uma materialidade, tem historicidade (...) a relação de funcionamento da língua é com o interdiscurso e não com a situação." Em virtude dessa relação da língua e dos sentidos com os discursos que os atravessam, as sistematicidades lingüísticas estão expostas "à não completude, à falha, ao engano".

Entretanto, há outros sentidos que são construídos na língua e envolvem diretamente o enuńciador, como aquele em que o falante/escritor precisa comentar suas próprias palavras, seja para reduzir os sentidos, seja para expor o termo a seus múltiplos sentidos. É o que AuthiER-REVUZ (1998: 29-49) denomina de glosas do enuncíador, quando este "as comenta ao mesmo tempo que as enuncia, um dizer que se volta explicitamente sobre si mesmo". O glosador se utiliza de dois mecanismos para produzir esses sentidos metalingüísticos: fixar explicitamente um sentido para o termo $\mathrm{X}$ ou solicitar explicitamente uma pluralidade de sentidos para X. No primeiro caso, o enunciador pretende eliminar de $\mathrm{X}$ um sentido inoportuno que $\mathrm{X}$ autoriza ou favorece, e colocar o seu sentido, o que se realiza através de glosas na forma negativa (não no sentido de q), que apresentam um sentido complementar que elimina a ameaça do sentido q; glosas na forma dupla (X no sentido de p e não no sentido de $q$ ); e a especificação positiva do sentido ( $X$, no sentido de $p)$, que faz intervir interpretativamente o outro sentido $q$, e para tanto recorre a modos de especificação de p: paráfrase de uma expressão complexa. sinonímia, dupla antonímia, contextualização adicional, caracterização-determinação.

Essas operações de metaenunciação são elaboradas no 'já-dito' de outros discursos que está sedimentado nas palavras; o enunciador marca uma posição no interdiscurso para defender-se dos sentidos de fora, de um exterior do discurso, que venha desestabilizar o seu próprio dizer. No segundo caso, a explicitação da pluralidade de sentidos se dá através de formas como também no sentido p, onde se especifica o outro sentido a ser acrescentado ao sentido tido como evidente; nos dois sentidos da palavra; em todos os sentidos da palavra (essas formas interpretam sentidos quase equivalentes), Segundo a autora, em sua conclusão, "no funcionamento do gesto 
metaenunciativo de explicitação do sentido de uma unidade lexical em contexto, o que me interessa sublinhar é a complexidade do que está em jogo no plano do sentido - redução contextual, explicitação e interpretação -, no ir e vir entre um contexto de Y que se mostra como insuficiente para determinar univocamente o sentido desse elemento $\mathrm{X}$ e uma explicitação que o supre, freqüentemente, não pelo modo autônomo de uma descrição onde 'se realizaria' o sentido de $Y$, mas desembocando num trabalho interpretativo apoiado ... no contexto" (idem, p.49, grifos da autora).

Falta-nos responder às questões sobre o não-sentido e o silêncio, e como esses diferentes sentidos (da enunciação, da metaenunciação e do discurso (em termos de não-sentido e de silêncio) se efetivam como discurso político.

O não-sentido e o silêncio são fronteiras discursivamente fluidas e simplesmente ocultadas pelo formalismo insistente da linguagem (pensada aqui como as diferentes línguas e seus usos), até porque não existe o indivíduo sem-sentido e sem-dizer. Esses dois fenômenos, no entanto, estão na fundação dos discursos e de seus sentidos. Segundo ORLANDI (1993:11-25), o percurso que vai do semsentido ao sentido se faz por três etapas: o seu apagamento por uma memória estabelecida de sentidos já ditos; a resistência ao apagamento e a conseqüente produção de outros sentidos; o retomo do que foi excluído pelo apagamento sobre o mesmo, deslocando esse repetível. Esse percurso, ao mesmo tempo que desloca sentidos, também instaura sentidos, já que entendemos 'dar sentido' como "construir limites, desenvolver domínios, descobrir sítios de significância, tomar possíveis gestos de interpretação" (op.cit., p. 15, itálicos da autora). Esse deslocar e dar sentidos, a autora denominou de discurso fundador, caracterizado como: a) o discurso que cria uma nova tradição, re-significa o que veio antes e institui aí uma outra memória; b) o discurso que instaura rupturas na filiação ideológica dos sítios significantes estabelecidos, produzindo um efeito de familiar e de evidente que se arraiga, no entanto, na memória permanente; c) o discurso que institui um outro lugar de sentidos, uma outra região para o repetível (a memória do dizer), região que vai organizar outros e outros sentidos. Em suma, o discurso fundador é aquele que estabelece um novo conjunto de formações discursivas, de onde se pode dizer uma outra identidade. 
Enquanto o não-sentido trava batalha com os sentidos já estabelecidos, o silêncio combate, numa luta quixotesca, com o ruído. com a ânsia do humano de dizer e de falar. O silêncio tem várias faces, entre as quais comentaremos a política do silêncio e a fundação do sentido. A política do silêncio se realiza como "tomar" a palavra, "tirar" a palavra, obrigar a dizer, fazer calar, silenciar etc. Segundo ORLANDI (1992:29-40), "o silêncio é fundante, o silêncio é a matéria significante por excelência". Num contexto em que o homem é obrigado a fazer sentido com palavras, o silêncio é o lugar onde a matéria significante se movimenta e produz novos sentidos, transformando a unicidade dos sujeitos e dos discursos. Segundo a autora en estudo, enquanto a fala organiza a dispersão do silêncio, este "não está disponivel à visibilidade, não é diretamente observável. lile passa pelas palavras. Não dura. Só é possível vislumbrá-lo de modo fugaz. Ele escorre por entre a trama das falas" (op. cit.:34).

Essa circulação de sentidos nos discursos, que vai desde a ausência total de sentidos, passando por significação de silêncios, até a instituição de novas maneiras de interpretação e de dar sentido às realidades, podemos encontrar nas reflexões de FORGET (1994: 19-33) sobre discurso politico, que a autora divide em discurso ocultação e discurso revelação. No primeiro caso, os discursos são distorções da realidade ou fachadas que camuflam interesses inadmissiveis; dessa forma, todo político adapta a verdade a seus interesses, a fim de aumentar o potencial elcitoral e preservar a margem de manobra política, o que leva a concluir pela existência de uma espécie de divórcio entre o discurso e a prática. No segundo caso, os discursos são a expressão de valores e princípios compartilhados no seio de um grupo político; assim sendo, através deles temos acesso ao pensamento político, às intenções dos estadistas, de um partido; menos do que invocar as realizações, recorremos ao discurso como indício de adesão a um projeto. Essas crenças em relação ao discurso político aparecem muitas vezes, problematicamente, no mesmo espaço discursivo, quando um autor denuncia uma determinada manobra manipulativo-ideológica de um discurso e, noutro trecho, cita o politico em questão para estabelecer uma prova. Diríamos que, em termos de análise discursiva, estabelece-se um jogo de sentidos onde os sujeitos operam enunciativa e metaenunciativamente com sentidos que ele quer dominar, mas se perde nas lacunas do silêncio e nos lugares do não-sentido do dizer. 
Em termos de análise, de todo o "corpus" disponível, recortaremos aqueles enunciados que definem e dizem o que é universidade. Como formalização da análise, servimo-nos do seguinte aparato simbólico: representamos a candidatura Jáder Nunes e Thompson Mariz por JT, a candidatura Luiz Renato e Maria Cláudia por LM e a candidatura Rubens Freire e Edilson Amorim por RE.

A enunciação recupera a memória do dizer do sujeito e coloca os sentidos num emaranhado de vozes que divide o discurso em diferentes interdiscursos: a tradição, a economia, a ciência, o senso comum, a política. Em JT, LM e RE, o discurso da tradição ecoa no sentido das expressões Universidade, Instituição, Universidade Pública (JT), Universidade, Universidade Funcional (LM). Universidade, MEC, UFPB (RE). Nas três Cartas, o termo universidade aparece em maiúsculas e com um sentido de instituição duradoura e tradicional, e, enunciativamente, diríamos que acontece como um pré-construído de outras falas políticas. Essa expressão, por ser comum aos três programas, tem seu sentido especificado pelas formações discursivas de cada carta: JT caracteriza-a como Instituição Pública, enunciação atravessada por um discurso de afirmação do que está, que defende o status quo; LM especifica tal expressão como Universidade Funcional, e situa-a como resultado de estudos da filósofa Marilena Chaui, o que dá a esse discurso uma feição política e técnica, na medida em que recorre a um argumento por autoridade para dizer e deixar o seu enunciado ser atravessado por discursos como: se essa autoridade fez um estudo e chegou a essa conclusão, então ela tem a verdade. Essa negação da universidade como ela está se repete na expressão projeto universitário do passado, atravessado por um discurso político de destruição da imagem do outro. Já RE qualifica a universidade numa clivagem entre MEC e UFPB; a universidade permanece com o sentido tradicional e político, mas está sujeita ao que enunciativamente significa como minguam as suas verbas (do MEC) e constante redução de verbas (da UFPB). Essas expressões trazem para o enunciado vozes de um discurso econômico. Como pudemos constatar, as três cartas-prograrna, já no nível do enunciado formal da língua e da escolha lexical, funcionam a partir de três formações discursivas (genericamente e por seu predomínio) distintas: as formações discursivas da situação, da tecnocracia científica e da política econômica. Essas formações discursivas são as 
regiões de onde o sujeito diz o seu discurso e delimita os campos do falar sobre a universidade.

Em termos de metaenunciação, as cartas-programa recorrem ao uso de termos e expressões como define, significa, não pode ser compreendida (JT), ou seja (LM), por mais que se diga (RE). Constatamos que, num momento, ocorre o sentido metalingüístico de fixar explicitamente um sentido para o termo universidade, através dos mecanismos da definição, da caracterização-determinação e da explicação, conforme podemos observar nos recortes abaixo:

Nada define melhor a Universidade do que ser uma Instituição produtora e socializadora do conhecimento.

Produzir conhecimentos significa voltar-se para a pesquisa (JT).

A reforma universitária implantou entre nós o que a filósofa Marilena Chaui denominou de Universidade Funcional, ou seja, uma estrutura de poder aparentemente despolitizada ( LM).

Por sua vez, em outro momento o sentido do termo universidade é fixado através do que Authier-Revuz denomina de glosas na forma negativa, quando o locutor precisa eliminar um sentido inoportuno que ameaça a descrição, definição ou caracterização que ele autoriza e favorece:

A Universidade não pode ser compreendida como uma instituição isolada (JT).

Por mais que se diga que há um crescimento no meio acadêmico, sobretudo nos discursos de posse de reitores, a universidade brasileira $e$, no seu interior, a UFPB sofre constante redução das verbas (RE).

Podemos afirmar que os sujeitos constroem os seus sentidos sob dois funcionamentos: aquele da formação discursiva a que ele se filia, quando as palavras e as expressões adquirem sentidos no discurso em que estão inseridas e estão situadas no plano da interdiscursividade e do funcionamento metaenunciativo; quando o sujeito se volta para as próprias palavras que usa, seja para especificálas ou avaliá-las, fenômeno que se situa no plano da intradiscursividade. Esse jogo entre a intra e a interdiscursividade caracteriza enunciativamente o discurso, na medida em que dá visibilidade ao próprio sujeito, às suas formações discursivas e à memória do dizer, criando nos leitores ou nos interlocutores a impressão de uma realidade já vista, já lida, já interpretada, em suma, 
já dada, o que se caracteriza como o efeito da ideologia sobre o sujeito. Entretanto, esse efeito de sentido de que tudo já está dito e feito, que transparece em enunciados como

O público é que pertence a todo o povo (JT).

A Universidade transformou-se numa coleção de especialistas (LM).

A UFPB sofre constante redução de verbas ( RE).

não se realiza de modo pacífico no discurso, mas este, em sua própria virtualidade de enunciação, mesmo quando não tem um locutor empírico que o realize, trava batalhas com o que a Análise de Discurso denomina de não-sentido e silêncio. Se olharmos os discursos em análise da perspectiva do não-sentido (entendido aqui como discursos que estabelecem novos lugares de onde se diz o sentido, ou seja, discurso fundador), constataremos que há uma formação discursiva, FD1, que aceita a situação como está e por essa razão faz sentido afirmar que o público pertence a todo o povo; há outra, a FD2, que faz sentido afirmando que a universidade é uma coleção de especialistas; e uma terceira, a FD3, que faz sentido afirmando estar a universidade sob constante redução de verbas. Temos três discursos que se entrecruzam - a situação, o tecnocrata e o econômico - e funcionam, dando sentido à universidade, em três etapas: apagam uma memória já estabelecida e re-significam a ordem anterior com uma nova memória, atribuem sentidos familiares e evidentes ao novo universo discursivo construído e estabelecem um outro lugar para dizer os novos sentidos evidentes. Para instaurar esse sentido fundador, é necessário controlar a polissemia e o equívoco da língua, o que é feito através de silêncios que oscilam entre o não-dizer e o dizer-negação.

A Universidade não pode abdicar de seu papel de instância critica.

A Universidade Pública é a que pertence à cidadania e está a serviço do bem comum ( JT).

Jamais tivemos universidades autônomas no Brasil.

Até hoje, não logramos superar a estrutura de poder moldada pela universidade funcional (LM).

A nossa visão prioriza a Universidade como um veículo que possibilite a incorporação de experiências socialmente acumuladas. 
A universidade tem deixado de exercer suas tarefas centrais (RE).

Podemos constatar, por esses recortes, que instância critica, universidade autônoma e incorporação de experiências sociais são os sentidos que as FDs querem estabelecer; entretanto, ficam em silêncio. ou por não serem dito ou por serem negados, os outros sentidos: o conformismo, a dependência e as experiências autoritárias.

No início deste ensaio, questionamos se os textos do gênero carta-programa, distribuídos numa universidade, numa campanha eleitoral para reitor, trazem características dessa instituição. O essencial da questão era saber se o texto, por ser distribuído numa universidade, traz necessariamente especificações de discurso acadêmico. Constatamos que os textos trazem diferentes qualidades do discurso acadêmico (a objetividade, a polêmica, citações, recorrência ao argumento por autoridade etc.), entretanto o que os caracteriza e diferencia dos textos efetivamente acadêmicos é que eles tanto interpretam os discursos dos outros segundo sua própria visão deformada de sujeitos, como procuram compartilhar de sentidos que sejam próprios de sua formação discursiva, negando os outros sentidos. Tais propriedades caracterizam esse discurso como politico.

\section{REFERÊNCIAS BIBLIOGRÁFICAS}

AUTHIER-REVUZ, Jaqueline. Palavras incertas: as não-coincidencias do dizer. Campinas: Ed. Unicamp, 1998. O enunciador glosador de suas palavras: explicitação e interpretação.

BARTHES, Roland. A aventura semiológica. Lisboa: Edições 70 , 1987.

FORGET, Danielle. Conquistas e resistências do poder. São Paulo: Edusp, 1994. Introdução.

GUIMARÃES, Eduardo. Os limites do sentido: um estudo histórico e enunciativo da linguagem. Campinas: Pontes, 1995. 
GUIMARÃES, Eduardo. Linguagem e mito: uma concepção de sentido e de texto. Línguas e Instrumentos Lingiüsticos. Campinas, Pontes, n.2,. p. 85-92, 1999.

ORLANDI, Eni. Discurso fundador: a formação do país e a construção da identidade nacional. Campinas: Pontes, 1993. Vão surgindo sentidos.

ORLANDI, Eni. As formas do silêncio: no movimento dos sentidos. Campinas: Ed. da Unicamp, 1992. Silêncio e sentido.

SCLIAR, Moacyr. Os leopardos de Kafka. São Paulo: Companhia das Letras, 2000. 